\section{Tireoide: a patologia dos núcleos}

Inês Vieira de Castro'

$\mathrm{O}$ reconhecimento definitivo da existência da variante folicular do carcinoma papilífero bem diferenciado da tireoide pela Organização Mundial da Saúde (OMS), em 1984, acompanhado da padronização dos critérios diagnósticos desta nova entidade, revolucionou o diagnóstico das neoplasias foliculares da tireoide. Enquanto o carcinoma folicular continuou a ser definido pela existência de invasão vascular ou capsular, o carcinoma papilífero deixou de ser caracterizado pela arquitetura papilífera e passou a ser diagnosticado por critérios nucleares (aspecto vazado, grooves, pseudoinclusões, entre outros). Desde que as alterações nucleares características estejam presentes, o tumor é diagnosticado como carcinoma papilífero, mesmo sem formação de papilas ou comportamento invasivo.

Ao se procurar rotineiramente as alterações nucleares do carcinoma papilífero em todos os nódulos da tireoide, os patologistas se deparam frequentemente com padrões intermediários de alterações nucleares. Enquanto alguns núcleos são facilmente identificáveis como do tipo folicular ou papilífero, outros exibem um espectro de alterações entre esses dois polos característicos. O carcinoma papilífero é caracterizado por um conjunto de alterações nucleares, mas nenhuma delas é patognomônica. Quais seriam, então, as alterações mínimas necessárias para um diagnóstico definitivo? Não há um consenso definitivo na literatura e isso levou a uma variabilidade intra e interobservador significativa no diagnóstico da variante folicular do carcinoma papilífero $(1,2)$. Mesmo entre especialistas em patologia da tireoide, o índice de concordância em casos selecionados varia de 39\% (em geral) a 66,7\% (em casos com metástases). O uso de marcadores imunoistoquímicos e moleculares pode favorecer a malignidade, mas não permite, por si só, um diagnóstico definitivo, sendo necessária a presença das alterações nucleares características (3-5).

As lesões classificadas como foliculares representam também um desafio diagnóstico. Ao se caracterizar o chamado "padrão folicular" no material obtido por punção aspirativa por agulha fina, continua sendo necessária a avaliação histológica do nódulo para o estudo de sua eventual cápsula. Não é possível diagnosticar malignidade apenas pelo aspecto citológico, e os marcadores imunoistoquímicos e moleculares ainda não permitem distinguir o carcinoma folicular das lesões adenomatosas benignas, podendo apenas favorecer uma ou outra possibilidade (3-5). Além disso, alguns desses casos acabam sendo reclassificados como variante folicular do carcinoma papilífero.

Este volume da revista da Associação Brasileira de Educação Médica (ABEM) traz um artigo de Ferreira e cols. que apresenta uma metodologia que pode contribuir para uma abordagem mais objetiva do padrão nuclear nas lesões foliculares da tireoide: a análise de imagem com avaliação da textura da cromatina nuclear (6). Foram estudadas variáveis morfométricas, densitométricas e de análise de textura visando à distinção entre os diferentes tipos de lesão folicular e tentando diferenciar lesões benignas de malignas. Os autores concluem que a análise de imagem pode ser útil no diagnóstico diferencial das lesões de padrão folicular, em conjunto com a análise morfológica clássica e a imu-
${ }^{1}$ Médica patologista do Centro de Diagnóstico Campinas, Campinas, SP, Brasil; doutora em Patologia, Faculdade de Medicina, Universidade de São Paulo (FMUSP), São Paulo, SP, Brasil

Correspondência para: Inês Vieira de Castro Centro de Diagnóstico Campinas Av. Andrade Neves, 707, conj. 806 13013-161 - Campinas, SP, Brasil i.v.castro@uol.com.br 
noistoquímica, sendo o HBME-1 o mais sensível marcador imunoistoquímico de malignidade nessa casuística. Ao incorporar um software à análise digital de imagem já realizada em alguns laboratórios de patologia, a metodologia pode ser aplicada na rotina diagnóstica, inclusive em material obtido por biópsia aspirativa por agulha fina.

Há poucos trabalhos publicados que utilizam análise da textura nuclear e morfometria no diagnóstico de lesões da tireoide, os quais também têm resultados promissores $(7,8)$. A validação dessa metodologia pode caracterizar uma nova arma diagnóstica na difícil tarefa de analisar os padrões nucleares nos nódulos da tireoide, uma das maiores dificuldades atuais na abordagem das neoplasias foliculares pelo patologista.

\section{REFERÊNCIAS}

1. Lloyd RV, Erickson LA, Casey MB, Lam KY, Lohse CM, Asa SL, et al. Observer variation in the diagnosis of follicular variant of papillary thyroid carcinoma. Am J Surg Pathol. 2004;28(10):1336-40.
2. Elsheikh TM, Asa SL, Chan JK, DeLellis RA, Heffess CS, LiVolsi $\mathrm{VA}$, et al. Interobserver and intraobserver variation among experts in the diagnosis of thyroid follicular lesions with borderline nuclear features of papillary carcinoma. Am J Clin Pathol. 2008;130(5):736-44.

3. Trovisco V, Soares P, Preto A, Castro P, Maximo V, Sobrinho-Simoes M. Molecular genetics of papillary thyroid carcinoma: great expectations. Arq Bras Endocrinol Metabol. 2007;51(5):643-53.

4. Cerutti JM. [Nodule diagnosed as follicular patterned lesion: Are biomarkers the promise?] Arq Bras Endocrinol Metabol. 2007;51(5):832-42.

5. Asa SL. The role of immunohistochemical markers in the diagnosis of follicular-patterned lesions of the thyroid. Endocr Pathol. 2005;16(4):295-309.

6. Ferreira RC, Ward LS, Adam RL, Leite NJ, Metze K, Matos PS. Contribution of nuclear texture analysis for the differential diagnosis of follicular lesions of the thyroid - comparison with immunohistochemical markers. Arq Bras Endocrinol Metabol. 2009;53(6).

7. Shapiro NA, PolozTL, Shkurupij VA, Tarkov MS, PolozVV, Demin AV. Application of artificial neural network for classification of thyroid follicular tumors. Anal Quant Cytol Histol. 2007;29(2):87-94.

8. Cochand-Priollet B, Koutroumbas K, Megalopoulou TM, Pouliakis A, Sivolapenko G, Karakitsos P. Discriminating benign from malignant thyroid lesions using artificial intelligence and statistical selection of morphometric features. Oncol Rep. 2006;15 Spec no.:1023-6. 